\title{
Resting Heart Rate and Ischemic Stroke in Patients with Heart Failure
}

\author{
Koki Nakanishi ${ }^{a}$ Marco R. Di Tullio ${ }^{a}$ Min Qian $^{b}$ John L.P. Thompson ${ }^{b}$
}

Arthur J. Labovitz $^{d}$ Douglas L. Mann ${ }^{\text {e Ralph L. Sacco }}{ }^{f}$ Patrick M. Pullicino $^{\text {n }}$

Ronald S. Freudenberger $^{g}$ John R. Teerlink ${ }^{h}$ Susan Graham ${ }^{i}$

Gregory Y.H. Lip ${ }^{\circ}$ Bruce Levin $^{\mathrm{b}}$ Jay P. Mohr ${ }^{\mathrm{c}}$ Richard Buchsbaum ${ }^{\mathrm{b}}$

Conrado J. Estolj Dirk J. Lok ${ }^{k}$ Piotr Ponikowski Stefan D. Anker ${ }^{m}$

Shunichi Homma ${ }^{a}$ WARCEF Investigators

\begin{abstract}
a Department of Medicine, Division of Cardiology, Columbia University Medical Center, ${ }^{b}$ Department of Biostatistics, Mailman School of Public Health, Columbia University Medical Center, 'Department of Neurology, Columbia University Medical Center, New York, NY, dUniversity of South Florida, Tampa, FL, eWashington University, St. Louis, MO, ${ }^{\mathrm{f}}$ University of Miami, Miami, FL, ${ }^{9}$ Lehigh Valley Hospital, Allentown, PA, h Section of Cardiology, San Francisco Veterans Affairs Medical Center and University of California San Francisco, San Francisco, CA, and iSUNY Upstate Medical University, Syracuse, NY, USA; 'ंCentro Neurológico de Tratamiento y Rehabilitación, Buenos Aires, Argentina; ${ }^{2}$ Deventer Hospital, Deventer, The Netherlands; 'Military Hospital, Wroclaw, Poland; m Department of Innovative Clinical Trials, University Medicine Göttingen (UMG), Göttingen, Germany; nUniversity of Kent, Canterbury, Kent, and ${ }^{\circ}$ University of Birmingham Centre for Cardiovascular Sciences, Birmingham, UK
\end{abstract}

\section{Keywords}

Beta-blocker - Heart failure - Ischemic stroke $\cdot$ Resting heart rate - Sinus rhythm - Warfarin versus Aspirin in Reduced Cardiac Ejection Fraction trial

\begin{abstract}
Background: Although high resting heart rate $(R H R)$ is known to be associated with an increased risk of mortality and hospital admission in patients with heart failure, the relationship between RHR and ischemic stroke remains unclear. This study is aimed at investigating the relationship between RHR and ischemic stroke in patients with heart failure in sinus rhythm. Methods: We examined 2,060 patients
\end{abstract}

\section{KARGER}

(c) 2017 S. Karger AG, Basel

E-Mail karger@karger.com

www.karger.com/ced with systolic heart failure in sinus rhythm from the Warfarin versus Aspirin in Reduced Cardiac Ejection Fraction trial. RHR was determined from baseline electrocardiogram, and was examined as both a continuous variable and a categorical variable using quartiles. Ischemic strokes were identified during follow-up and adjudicated by physician review. Results: During 3.5 \pm 1.8 years of follow-up, 77 patients $(5.3 \%$ from Kaplan-Meier [KM] curve) experienced an ischemic stroke. The highest incidence of ischemic stroke (21/503 [KM $6.9 \%$ ]) was observed in the lowest RHR quartile (RHR $<64$ beats/min) compared to other groups; 22/573 (KM 5.3\%) in 64-70 beats/min, 13/465 (KM 3.5\%) in 71-79 beats/min, and $21 / 519$ (KM 5.4\%) in RHR $>79$ beats/min ( $p=0.693$ ). Multivariable Cox proportional hazards analysis revealed that $\mathrm{RHR}$ 
was significantly associated with ischemic stroke (hazard ratio per unit decrease: $1.07,95 \% \mathrm{Cl} 1.02-1.13$, when $\mathrm{RHR}<64$ / beats $/ \mathrm{min} ; p=0.038$ ), along with a history of stroke or transient ischemic attack and left ventricular ejection fraction. Conclusions: In contrast to its beneficial effect on mortality and hospital re-admissions, lower RHR may increase the risk of ischemic stroke in patients with systolic heart failure in sinus rhythm.

(c) 2017 S. Karger AG, Basel

\section{Introduction}

Approximately 5.7 million adults are living with heart failure in the United States, and the prevalence is increasing [1]. Among heart failure patients, approximately half have reduced left ventricular ejection fraction (LVEF). Heart failure with reduced LVEF (HFrEF) is a major cause of mortality and hospital admission, and a high resting heart rate (RHR) is a strong predictor of mortality and hospital re-admission in patients with HFrEF [2-4]. Beta-adrenoceptor-blocking agents (beta-blockers) are now well established as a mandatory therapy in patients with HFrEF [5-8], and part of their beneficial effect may depend on RHR reduction [9-11]. However, the relationship between RHR and ischemic stroke risk in HFrEF is still unclear, although HFrEF is associated with an increased risk for cardioembolic stroke $[12,13]$. The aim of this study was to investigate the relationship between RHR and ischemic stroke in HFrEF patients in sinus rhythm who were treated with beta-blockers.

\section{Methods}

\section{Patients}

We analyzed data from the Warfarin versus Aspirin in Reduced Cardiac Ejection Fraction (WARCEF) trial, which compared warfarin and aspirin in a double-blind, randomized design [14]. The results of the primary analysis have been previously published [15]. WARCEF obtained data from 168 centers in 11 countries, and enrolled 2,305 patients with follow-up periods of up to 6 years (mean $3.5 \pm 1.8$ years). Patients were $>18$ years of age and had normal sinus rhythm and LVEF $\leq 35 \%$ within 3 months before randomization. All patients were treated with guideline-recommended medical treatment. Since approximately $90 \%$ of patients were treated with betablockers, which affect RHR, we limited our analysis to only these patients. A total of 243 patients who were not treated with betablockers were excluded from the study. Two others were excluded because they did not have RHR information. The final sample for analysis thus included 2,060 patients. RHR was obtained from the baseline electrocardiogram. The study was approved by the institutional review boards and ethics boards of participating centers.
Assessment of Established and Potential Risk Factors of

Ischemic Stroke

The clinical characteristics included in our study were age, sex, hypertension, diabetes mellitus, current smoking status and alcohol consumption, history of myocardial infarction (MI), history of atrial fibrillation (AF), prior stroke/transient ischemic attack (TIA), education level, New York Heart Association (NYHA) class, systolic and diastolic blood pressures (BP), pulse pressure, medications, implantable cardioverter defibrillator, and LVEF. LVEF on either quantitative echocardiography, radionuclide or contrast ventriculography was obtained in all patients within 3 months before randomization.

\section{Follow-Up}

Follow-up was performed monthly by telephone or in person. An in-person assessment was conducted quarterly for clinical evaluation. Stroke was defined as a clinically relevant new lesion detected on computed tomography or magnetic resonance imaging or, in the absence of a new lesion, clinical findings that were consistent with the occurrence of clinical stroke and that lasted for longer than $24 \mathrm{~h}$.

\section{Statistical Analysis}

Categorical variables are presented as number/total number (\%) and compared by quartiles of RHR using chi-square test or Fisher exact test. Continuous variables are presented as mean \pm SD and compared using the ANOVA F test. Kaplan-Meier (KM) estimates for ischemic stroke, stratified by quartiles of RHR, were also calculated. Univariable and multivariable linear regression analyses were conducted to determine the variables independently associated with RHR. Univariable and multivariable Cox proportional hazards regression analyses were then performed to identify the association between RHR and ischemic stroke. The linearity of associations was assessed using restricted cubic splines and, if a trend of non-linearity was found $(p<0.10)$, a linear spline or quadratic or cubic polynomial transformation was chosen based on the univariable Akaike's information criterion (AIC). To compare the association of RHR with ischemic stroke in aspirin- and warfarin-treated subgroups, we added treatment and its interaction with RHR to the Cox models. Multivariable analyses were performed in 2 models. Model 1: adjustment by variables with significant association with ischemic stroke in univariable Cox proportional hazard analysis, and model 2: adjustment as in model 1 plus variables with significant association with RHR in univariable linear regression analysis. Missing values for the covariates were imputed using means for continuous variables and model values for categorical variables. Differences were considered significant at $p<0.052$-sided. Statistical analyses were performed using SAS 9.4 software (SAS Institute, Cary, NC, USA).

\section{Results}

The study sample had a mean age of $60 \pm 11$ years and a mean heart rate of 71 beats/min (median 70 beats $/ \mathrm{min}$, 25 th -75 th percentile $64-80$ beats $/ \mathrm{min}$ ). Baseline characteristics stratified by RHR quartiles are shown in Table 1 . 
Table 1. Baseline characteristics stratified by RHR

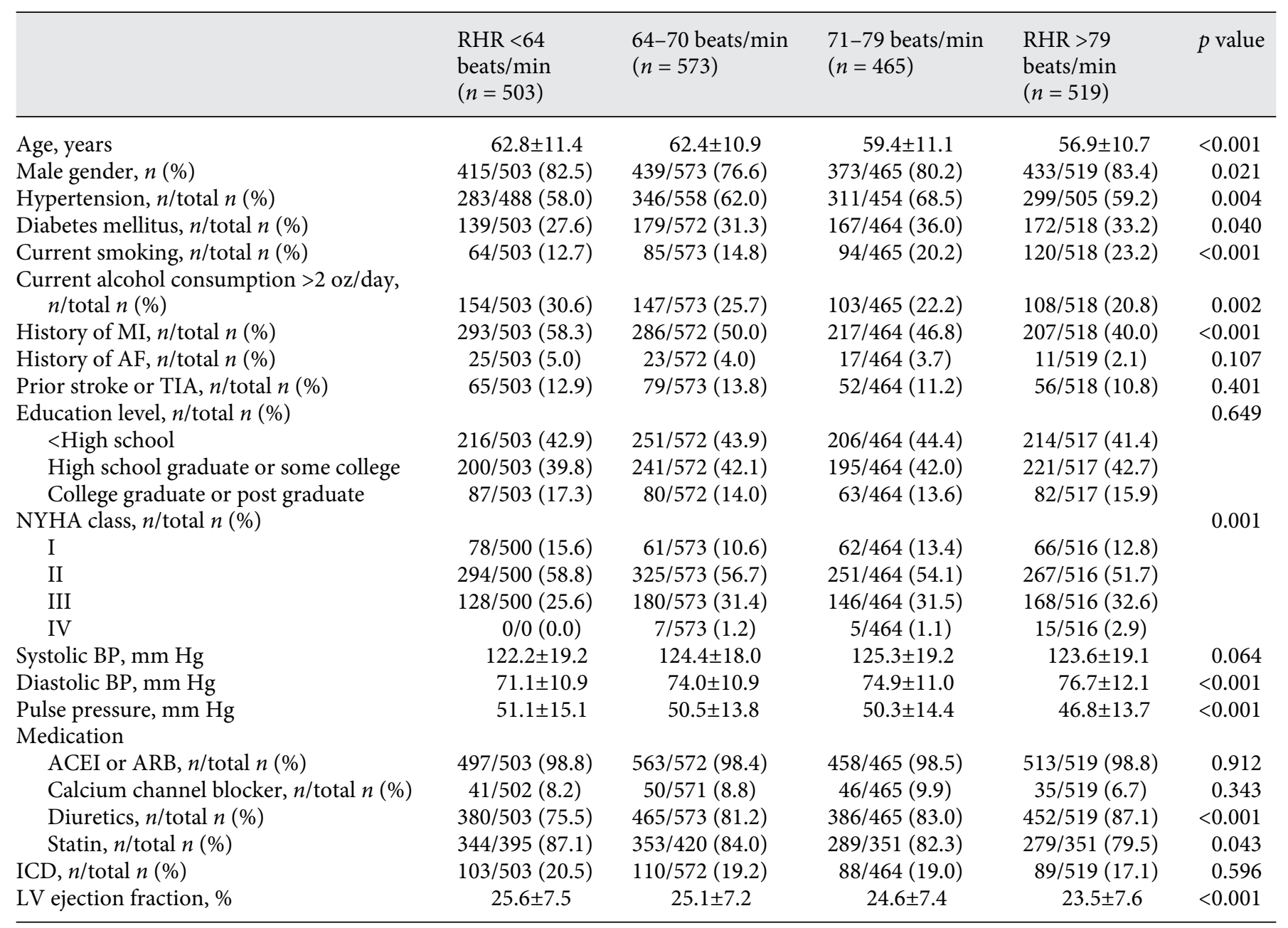

ACEI, angiotensin-converting enzyme inhibitor; AF, atrial fibrillation; ARB, angiotensin receptor blocker; BP, blood pressure; ICD, implantable cardioverter defibrillator; LV, left ventricle; MI, myocardial infarction; NYHA, New York Heart Association; RHR, resting heart rate; TIA, transient ischemic attack.

The factors independently associated with RHR in a multivariablelinear regression analysis were age $(\beta$-coefficient $-0.132, p<0.001)$, diabetes mellitus ( $\beta$-coefficient 2.188 , $p<0.001$ ), current smoking ( $\beta$-coefficient 2.614, $p<$ 0.001 ), current alcohol consumption $>2$ oz/day ( $\beta$ coefficient $-2.037, p<0.001)$, history of MI ( $\beta$-coefficient $-2.085, p<0.001)$, history of AF $(\beta$-coefficient $-3.448, p=$ $0.008)$, NYHA class ( $\beta$-coefficient $1.609, p=0.003$ ), diastolic BP $(\beta$-coefficient $0.169, p<0.001)$, pulse pressure ( $\beta$-coefficient $-0.061, p=0.001)$, diuretics $(\beta$-coefficient: 2.037, $p=0.002)$, and LVEF ( $\beta$-coefficient $-0.134, p<$ 0.001 ; Table 2).

During $3.5 \pm 1.8$ years of follow-up, 77 patients ( $5.3 \%$ from KM curve) developed ischemic stroke. The highest incidence of ischemic stroke (21/503 [KM 6.9\%]) was observed in the lowest RHR quartile (RHR $<64$ beats/ min) compared to other groups; 22/573 (KM 5.3\%) in 64-70 beats/min, 13/465 (KM 3.5\%) in 71-79 beats/ $\mathrm{min}$, and $21 / 519$ (KM 5.4\%) in RHR $>79$ beats/min $(p=$ $0.693)$.

A trend of nonlinear association between RHR and stroke was found $(p=0.08)$, and a linear spline with knot at $\mathrm{RHR}=64$ beats $/ \mathrm{min}$ was selected as the best model based on AIC. The hazard ratio (HR) plot is displayed in Figure 1. Results from Cox models are presented in Table 3. Overall, low RHR was a significant predictor of stroke (adjusted $p=0.044$ in model 1). In particular, the risk of stroke increased with decreasing RHR for RHR 
Table 2. Univariable and multivariable linear regression analysis for the determinants of RHR

\begin{tabular}{|c|c|c|c|c|c|}
\hline & For a change of & $\beta$-coefficient $(95 \% \mathrm{CI})$ & $p$ value & $\beta$-coefficient (95\% CI) & $p$ value \\
\hline Gender, male & & $0.121(-1.175$ to 1.418$)$ & 0.855 & & \\
\hline Hypertension & & $0.179(-0.882$ to 1.240$)$ & 0.740 & & \\
\hline Diabetes mellitus & & $1.220(0.120$ to 2.319$)$ & 0.030 & 2.188 (1.116 to 3.259$)$ & $<0.001$ \\
\hline History of MI & & $-3.326(-4.342$ to -2.310$)$ & $<0.001$ & $-2.085(-3.105$ to -1.064$)$ & $<0.001$ \\
\hline History of AF & & $-3.424(-6.141$ to -0.707$)$ & 0.014 & $-3.448(-6.004$ to -0.892$)$ & 0.008 \\
\hline Prior stroke or TIA & & $-1.098(-2.662$ to 0.467$)$ & 0.169 & & \\
\hline Education level & Ref.: <high school & & 0.522 & & \\
\hline High school graduate or some college & & $0.255(-0.858$ to 1.368$)$ & & & \\
\hline Pulse pressure, $\mathrm{mm} \mathrm{Hg}$ & 1 unit increase & $-0.100(-0.136$ to -0.065$)$ & $<0.001$ & $-0.061(-0.097$ to -0.025$)$ & 0.001 \\
\hline ACEI or ARB & & $1.009(-3.420$ to 5.438$)$ & 0.655 & & \\
\hline Calcium channel blocker & & $-0.750(-2.603$ to 1.104$)$ & 0.428 & & \\
\hline Diuretics & & $3.268(1.950$ to 4.587$)$ & $<0.001$ & $2.037(0.757$ to 3.318$)$ & 0.002 \\
\hline Statin & & $-1.986(-3.549$ to -0.423$)$ & 0.013 & $-0.785(-2.296$ to 0.727$)$ & 0.309 \\
\hline ICD & & $-1.250(-2.558$ to 0.058$)$ & 0.061 & & \\
\hline LV ejection fraction, \% & 1 unit increase & $-0.194(-0.262$ to -0.126$)$ & $<0.001$ & $-0.134(-0.200$ to -0.068$)$ & $<0.001$ \\
\hline
\end{tabular}

ACEI, angiotensin-converting enzyme inhibitor; AF, atrial fibrillation; ARB, angiotensin receptor blocker; BP, blood pressure; ICD, implantable cardioverter defibrillator; LV, left ventricle; MI, myocardial infarction; NYHA, New York Heart Association; RHR, resting heart rate; TIA, transient ischemic attack.

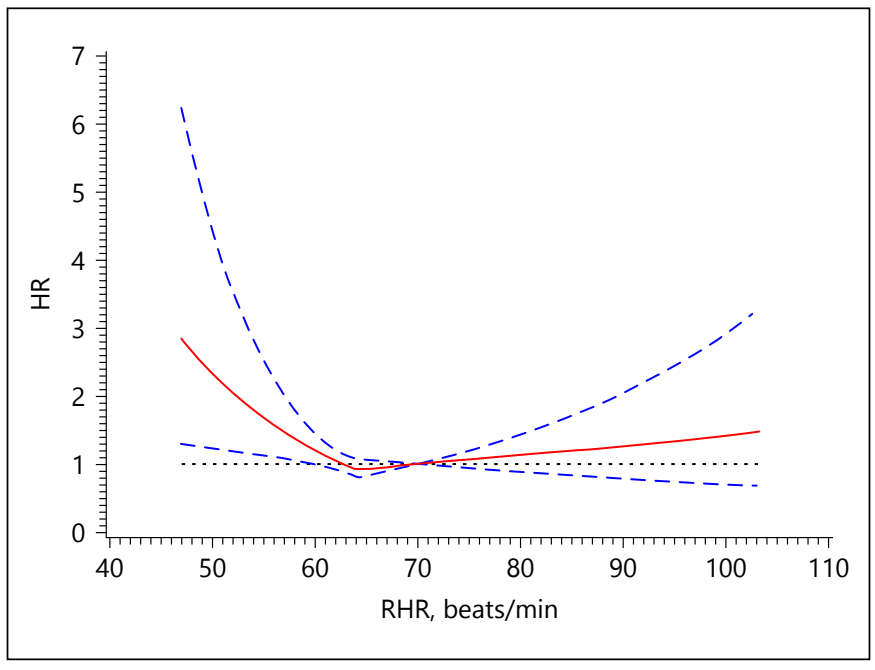

Fig. 1. Risk of ischemic stroke by RHR. Each HR was computed with the median heart rate value of 70 beats/min as the reference (red solid line). Blue dashed-lines represent 95\% CI and black dashed-line represents HR 1.0. RHR, resting heart rate; HR, hazard ratio. values $<64$ beats/min (adjusted HR 1.07, $p=0.013$ ), while it was unaffected above that value (adjusted HR 0.99, $p=$ $0.355)$. Ischemic stroke was also significantly associated with the history of stroke or TIA (adjusted HR 3.42, $p<$ 0.001 ) and LVEF (quadratic model, overall $p<0.001,75$ th vs. 25 th percentile adjusted HR 0.82 ). Even after adjustment for additional variables with significant association with RHR (age, diabetes mellitus, current smoking, current alcohol consumption, history of $\mathrm{MI}$, history of $\mathrm{AF}$, NYHA class, diastolic BP, pulse pressure, diuretics, and statin), RHR remained significantly associated with ischemic stroke (Table 3, model 2).

Table 4 shows the relationship between RHR and stroke risk in warfarin- and aspirin-treated subgroups. The interaction model results showed that lower RHR was significantly associated with ischemic stroke among patients randomized to aspirin $(p=0.039)$, whereas there was no relationship in those randomized to warfarin $(p=$ $0.408)$. This result persisted after adjustment for variables with significant association with RHR (Table 4, model 2). 
Table 3. Univariate and multivariate Cox proportional hazards regression analysis for ischemic stroke

\begin{tabular}{|c|c|c|c|c|c|c|c|}
\hline & \multirow[t]{2}{*}{ For a change of } & \multicolumn{2}{|l|}{ Univariable } & \multicolumn{2}{|c|}{ Multivariable model 1} & \multicolumn{2}{|c|}{ Multivariable model 2} \\
\hline & & HR (95\% CI) & $p$ value & HR (95\% CI) & $p$ value & HR (95\% CI) & $p$ value \\
\hline \multirow[t]{3}{*}{ RHR, beats/min } & Linear spline & & 0.034 & & 0.044 & & 0.038 \\
\hline & 1 unit decrease when $\mathrm{RHR}<64$ & $1.07(1.02-1.12)$ & 0.009 & $1.07(1.01-1.12)$ & 0.013 & $1.07(1.02-1.13)$ & 0.011 \\
\hline & 1 unit decrease when RHR $\geq 64$ & $0.99(0.96-1.01)$ & 0.325 & $0.99(0.97-1.01)$ & 0.355 & $0.99(0.96-1.01)$ & 0.271 \\
\hline Age, years & 1 unit increase & $1.01(0.99-1.03)$ & 0.374 & & & $1.01(0.98-1.03)$ & 0.605 \\
\hline Gender, male & & $0.88(0.52-1.52)$ & 0.655 & & & & \\
\hline Hypertension & & $0.95(0.60,1.50)$ & 0.829 & & & & \\
\hline Diabetes mellitus & & $1.27(0.80-2.03)$ & 0.306 & & & $1.16(0.71-1.91)$ & 0.555 \\
\hline Current smoking & & $1.03(0.58-1.83)$ & 0.928 & & & $0.99(0.55-1.81)$ & 0.986 \\
\hline Current alcohol consumption & & $0.80(0.46-1.38)$ & 0.415 & & & $0.81(0.46-1.44)$ & 0.479 \\
\hline History of MI & & $1.37(0.88-2.16)$ & 0.166 & & & $1.29(0.79-2.08)$ & 0.309 \\
\hline History of AF & & $1.10(0.35-3.48)$ & 0.876 & & & $1.21(0.38-3.91)$ & 0.744 \\
\hline Prior stroke or TIA & & $3.22(1.98-5.25)$ & $<0.001$ & $3.42(2.09-5.59)$ & $<0.001$ & $3.36(2.04-5.54)$ & $<0.001$ \\
\hline Education level & Ref.: <high school & & 0.891 & & & & \\
\hline $\begin{array}{l}\text { High school graduate or some } \\
\text { college }\end{array}$ & & $1.05(0.64-1.73)$ & & & & & \\
\hline $\begin{array}{l}\text { College graduate or post } \\
\text { graduate }\end{array}$ & & $1.17(0.62-2.20)$ & & & & & \\
\hline NYHA class III or IV & & $1.03(0.63-1.66)$ & 0.913 & & & $0.90(0.55-1.48)$ & 0.673 \\
\hline Systolic BP, mm Hg & 1 unit increase & $1.00(0.99-1.01)$ & 0.880 & & & & \\
\hline Diastolic BP, mm Hg & 1 unit increase & $1.00(0.98-1.02)$ & 0.772 & & & $1.00(0.98-1.02)$ & 0.853 \\
\hline Pulse pressure, $\mathrm{mm} \mathrm{Hg}$ & 1 unit increase & $1.00(0.98-1.02)$ & 0.970 & & & $1.00(0.98-1.01)$ & 0.727 \\
\hline ACEI or ARB & & $1.17(0.16-8.38)$ & 0.879 & & & & \\
\hline Calcium channel blocker & & $0.42(0.13-1.34)$ & 0.143 & & & & \\
\hline Diuretics & & $1.04(0.58-1.86)$ & 0.889 & & & $1.06(0.58-1.93)$ & 0.848 \\
\hline Statin & & $0.94(0.43-2.06)$ & 0.870 & & & $0.88(0.39-1.98)$ & 0.761 \\
\hline ICD & & $0.59(0.30-1.19)$ & 0.140 & & & & \\
\hline \multirow[t]{2}{*}{ LV ejection fraction, \% } & Quadratic & & $<0.001$ & & & & \\
\hline & 75th vs. 25 th percentiles & $0.85(0.66-1.11)$ & & $0.82(0.63-1.07)$ & $<0.001$ & $0.83(0.63-1.09)$ & $<0.001$ \\
\hline
\end{tabular}

ACEI, angiotensin-converting enzyme inhibitor; AF, atrial fibrillation; ARB, angiotensin receptor blocker; $\mathrm{BP}$, blood pressure; HR, hazard ratio; ICD, implantable cardioverter defibrillator; LV, left ventricle; MI, myocardial infarction; NYHA, New York Heart Association; RHR, resting heart rate; TIA, transient ischemic attack.

In patients with RHR $<64$ beats/min, significantly lower ischemic stroke rate was observed in the warfarin group compared to the aspirin group (5/235 [KM 4.4\%] vs. $16 / 268$ [KM 9.2\%], $p=0.034$ ), whereas ischemic stroke rate did not differ between the 2 treatment groups in patients with $\mathrm{RHR} \geq 64$ beats/min $(22 / 790$ [KM 3.6\%] vs. $34 / 767[\mathrm{KM} \mathrm{6.0 \% ],} p=0.086)$.

\section{Discussion}

This study demonstrates for the first time that low RHR is associated with a higher incidence of ischemic stroke among patients with HFrEF who are in sinus rhythm and are treated with currently recommended medical regimen, including beta-blockers.
In patients with HFrEF who are in sinus rhythm, a high RHR is associated with increased mortality and hospital re-admissions [2-4], and beta-blockers substantially improve the outcome [5-8]. Although the benefits of beta-blockers may not be entirely related to RHR reduction, several meta-analyses have shown a stronger effect on survival for RHR rather than the beta-blockers dose achieved [9-11]. As a result, it has become a common clinical assumption that the beneficial effect of betablockers depends on, or is heralded by, their RHR-lowering effect: the slower the RHR, the greater the benefit. However, although HFrEF is associated with an increased risk for cardioembolic stroke $[12,13]$, the relationship between RHR and ischemic stroke has not been fully investigated in patients with HFrEF in sinus rhythm. Here, we report for the first time that low RHR was associated 
Table 4. Unadjusted and adjusted Cox proportional hazards regression analysis for ischemic stroke in warfarin and aspirin subgroups

\begin{tabular}{|c|c|c|c|c|c|c|c|}
\hline & For a change of & HR (95\% CI) & $p$ value & HR (95\% CI) & $p$ value & HR (95\% CI) & $p$ value \\
\hline beats/min & 1 unit decrease when RHR $<64$ & $1.04(0.93-1.15)$ & 0.484 & $1.04(0.93-1.15)$ & 0.529 & $1.04(0.93-1.16)$ & 0.520 \\
\hline & 1 unit decrease when $\mathrm{RHR} \geq 64$ & $0.97(0.93-1.01)$ & 0.180 & $0.97(0.93-1.01)$ & 0.181 & $0.97(0.93-1.01)$ & 0.123 \\
\hline RHR (aspirin group), beats/min & Linear spline & & 0.032 & & 0.039 & & 0.037 \\
\hline Warfarin by RHR interaction & & & 0.340 & & 0.318 & & 0.259 \\
\hline Age, years & 1 unit increase & & & & & $1.01(0.99-1.03)$ & 0.469 \\
\hline Diabetes & & & & & & $1.16(0.70-1.91)$ & 0.559 \\
\hline Current smoking & & & & & & $1.01(0.56-1.84)$ & 0.968 \\
\hline Current alcohol consumption & & & & & & $0.79(0.45-1.40)$ & 0.424 \\
\hline Diastolic BP, mm Hg & 1 unit increase & & & & & $1.00(0.98-1.02)$ & 0.694 \\
\hline Pulse pressure, $\mathrm{mm} \mathrm{Hg}$ & 1 unit increase & & & & & $1.00(0.98-1.01)$ & 0.650 \\
\hline Diuretics & & & & & & $1.08(0.59-1.97)$ & 0.800 \\
\hline Statin & & & & & & $0.88(0.39-1.99)$ & 0.759 \\
\hline \multirow[t]{2}{*}{ LV ejection fraction, $\%$} & Quadratic & & & & & & \\
\hline & 75th vs. 25 th percentiles & & & $0.82(0.63-1.07)$ & $<0.001$ & $0.83(0.63-1.09)$ & $<0.001$ \\
\hline
\end{tabular}

AF, atrial fibrillation; BP, blood pressure; HR, hazard ratio; LV, left ventricle; MI, myocardial infarction; NYHA, New York Heart Association; RHR, resting heart rate; TIA, transient ischemic attack.

with a higher incidence of ischemic stroke in patients with HFrEF in sinus rhythm. Our finding was unexpected, because low RHR is usually associated with lower mortality and rate of hospital admission in these patients [2-4]. The relationship between heart rate and stroke still remains unclear in other clinical settings, where conflicting results have been reported [16-21]. Mao et al. [18] showed that high RHR increased the risk of stroke in 169,871 general Chinese adults $\geq 40$ years. Similarly, data from patients with stable coronary artery disease and hypertension demonstrated that high RHR was associated with an increased risk of stroke [19, 20]. More recently, the Reasons for Geographic and Racial Differences in Stroke study conducted in 24,730 subjects without history of stroke showed that each 10 beats/min increase in heart rate was associated with a $10 \%$ increase in the risk of stroke [21]. In contrast, reports from the general French population and the Women's Health Initiative Study did not show an association between RHR and stroke $[16,17]$.

The underlying mechanisms of our finding are unclear, but several potential explanations can be hypothe- sized. Recent studies have reported that low RHR is associated with higher incidence of AF development in various populations [22-24]. Bohm et al. [22] reported that RHR lower than 60 beats/min was associated with increased incidence of $\mathrm{AF}$ in 27,064 patients with high cardiovascular risk during a mean follow-up period of 4.7 years. O'Neal et al. [23] also reported that RHR lower than 60 beats/min was an independent risk for AF development in 5,226 elderly individuals from the general population. In our study, patients with low RHR may have more frequently developed transient episodes of AF during follow-up, which might be involved in their higher risk for ischemic stroke. Another possible mechanism could be an increase in central aortic pressure secondary to heart rate lowering. Bradycardia leads to dyssynchrony or uncoupling between outgoing and reflected waves, thereby elevating the central aortic pressure. In the Conduit Artery Functional Evaluation study [25], significantly higher central aortic systolic BP was observed with beta-blocker treatment compared with calcium channel blocker treatment despite similar effect on peripheral BP, resulting in a higher incidence of stroke in patients with 
hypertension. Finally, an increase in pulse pressure may also contribute to the development of stroke in HFrEF patients with low RHR. Because the mean arterial pressure is a product of cardiac output (heart rate stroke volume) and peripheral vascular resistance, low RHR should result in higher stroke volume to maintain cardiac output. A higher stroke volume, in turn, causes elevated pulse pressure which has been recognized as an independent predictor of stroke [26, 27]. Indeed, RHR was negatively correlated with pulse pressure in our population. However, pulse pressure was not significantly associated with ischemic stroke.

Interestingly, when patients were divided into subgroups on the basis of assigned antithrombotic treatment, low RHR was associated with ischemic stroke in the aspirin group, but not in the warfarin group. In patients with RHR $<64$ beats/min, patients treated with warfarin had significantly lower ischemic stroke rate than those with aspirin. This result suggests that systemic anticoagulation may counteract the risk of stroke associated with low RHR, and also suggests a potential thromboembolic component for the stroke mechanism. Furthermore, it may indicate that warfarin treatment may be preferable to aspirin treatment for stroke prevention in patients with low RHR.

Among medications that affect heart rate, ivabradine is a novel HF medication that specifically inhibits the $I_{f}$ current in the sinoatrial node, thereby lowering the heart rate without affecting the other aspects of cardiac function [28]. In Systolic Heart failure treatment with the - $f$ inhibitor ivabradine Trial, RHR reduction with ivabradine was associated with $26 \%$ risk reduction of first HF hospitalization, and $11 \%$ risk reduction of first allcause hospitalization [29]. Because of the study period of WARCEF trial (from October 2002 through January 2010), ivabradine was not used. Future studies are needed to investigate the association of RHR with ischemic stroke in patients treated with ivabradine.

\section{Study Limitations}

Our study has several limitations. Because we enrolled patients with HFrEF in sinus rhythm, the results may not be generalizable to patients with HF with preserved LVEF and to those with AF. Because of the absence of information on beta-blocker dose, we cannot evaluate a possible effect of different doses on our results. However, several meta-analyses have shown a stronger relationship between the RHR and prognosis in HF than between betablockers dose and prognosis [9-11]. Finally, although we performed multivariable analyses adjusting for ischemic stroke risk factors and variables associated with RHR, we cannot rule out the possibility of unmeasured confounders playing a role in the observed associations.

\section{Conclusions}

In contrast to the beneficial effect of lower RHR on mortality and hospital admissions, lower RHR increased the risk of ischemic stroke in HFrEF patients in sinus rhythm treated with beta-blockers. Further studies are required to evaluate the mechanisms for the increased risk of ischemic stroke in patients with low RHR.

\section{Acknowledgments}

We thank Michelle Bierig, RDCS, and Rui Liu, MD, for their help with the echocardiographic measurements.

\section{Sources of Funding}

The study was funded by U01-NS-043975 (Dr. Shunichi Homma) and U01-NS-039143 (Dr. John L.P. Thompson) from the National Institute of Neurological Disorders and Stroke.

\section{Disclosure Statement}

Dr. Shunichi Homma reports receiving payment from AGA Medical (now St. Jude Medical) for his work as a member of a data and safety monitoring board and consulting fees from Boehringer Ingelheim. Dr. Bruce Levin reports receiving consulting fees from United Healthcare. Dr. John R. Teerlink reports receiving research grants or consulting fees from Amgen, Bayer, Cardio3 Bioscience, Cytokinetics, Mast Therapeutics, Medtronic, Novartis, St. Jude, and Trevena. Dr. Arthur J. Labovitz reports receiving grant support from Boehringer Ingelheim and BMS Pfizer, lecture fees from Boehringer Ingelheim, and fees for the development of educational presentations from the American College of Cardiology. Dr. Stefan D. Anker reports receiving consulting fees from Vifor, Bayer, Janssen, Novartis, Relypsa, ZS-Pharma, and Thermo Fisher; grant support from Vifor Pharma, and Abbott Vascular; and lecture fees from Vifor, Novartis, and Stealth Peptides. Dr. Piotr Ponikowski reports receiving consulting fees from Bayer, Boehringer Ingelheim, Coridea, Corthera, Johnson \& Johnson, Pfizer, Respicardia, and Vifor Pharma; grant support from Vifor Pharma on behalf of himself and his institution; and lecture fees from Abbott, Boehringer Ingelheim, Merck Serono, Pfizer, Respicardia, Sanofi-Aventis, Servier, and Vifor Pharma. Dr. Gregory Y.H. Lip reports receiving consulting fees from Bayer/Janssen, Astellas, Merck, Sanofi, BMS/Pfizer, Biotronik, Medtronic, Portola, Boehringer Ingelheim, Microlife, and Daiichi-Sankyo; speakers bureau fees from Bayer, BMS/Pfizer, Medtronic, Boehringer Ingelheim, Microlife, Roche, and Daiichi-Sankyo; and payment for the development of educational presentationsfrom Bayer, Boehringer Ingelheim, and Merck. The other authors report no conflicts. 


\section{References}

1 Mozaffarian D, Benjamin EJ, Go AS, Arnett DK, Blaha MJ, Cushman M, Das SR, de Ferranti S, Despres JP, Fullerton HJ, Howard VJ, Huffman MD, Isasi CR, Jimenez MC, Judd SE, Kissela BM, Lichtman JH, Lisabeth LD, Liu S, Mackey RH, Magid DJ, McGuire DK, Mohler ER 3rd, Moy CS, Muntner P, Mussolino ME, Nasir K, Neumar RW, Nichol G, Palaniappan L, Pandey DK, Reeves MJ, Rodriguez CJ, Rosamond W, Sorlie PD, Stein J, Towfighi A, Turan TN, Virani SS, Woo D, Yeh RW, Turner MB: Heart disease and stroke statistics-2016 update: a report from the American Heart Association. Circulation 2016;133:e38-e360.

2 Pocock SJ, Wang D, Pfeffer MA, Yusuf S, McMurray JJ, Swedberg KB, Ostergren J, Michelson EL, Pieper KS, Granger CB: Predictors of mortality and morbidity in patients with chronic heart failure. Eur Heart J 2006; 27:65-75.

3 Bohm M, Swedberg K, Komajda M, Borer JS, Ford I, Dubost-Brama A, Lerebours G, Tavazzi L: Heart rate as a risk factor in chronic heart failure (SHIFT): the association between heart rate and outcomes in a randomised placebo-controlled trial. Lancet 2010;376:886-894.

4 Li SJ, Sartipy U, Lund LH, Dahlstrom U, Adiels M, Petzold M, Fu M: Prognostic significance of resting heart rate and use of $\beta$-blockers in atrial fibrillation and sinus rhythm in patients with heart failure and reduced ejection fraction: findings from the Swedish Heart Failure Registry. Circ Heart Fail 2015;8:871-879.

5 The cardiac insufficiency bisoprolol study II (CIBIS-II): a randomised trial. Lancet 1999; 353:9-13.

6 Effect of metoprolol CR/XL in chronic heart failure: metoprolol CR/XL randomised intervention trial in congestive heart failure (MERIT-HF). Lancet 1999;353:2001-2007.

7 Packer M, Coats AJ, Fowler MB, Katus HA, Krum H, Mohacsi P, Rouleau JL, Tendera M, Castaigne A, Roecker EB, Schultz MK, DeMets DL: Effect of carvedilol on survival in severe chronic heart failure. N Engl J Med 2001;344:1651-1658.

8 Packer M, Fowler MB, Roecker EB, Coats AJ, Katus HA, Krum H, Mohacsi P, Rouleau JL, Tendera M, Staiger C, Holcslaw TL, AmannZalan I, DeMets DL: Effect of carvedilol on the morbidity of patients with severe chronic heart failure: results of the carvedilol prospective randomized cumulative survival (COPERNICUS) study. Circulation 2002;106: 2194-2199.

9 Flannery G, Gehrig-Mills R, Billah B, Krum $\mathrm{H}$ : Analysis of randomized controlled trials on the effect of magnitude of heart rate reduction on clinical outcomes in patients with systolic chronic heart failure receiving betablockers. Am J Cardiol 2008;101:865-869.

10 McAlister FA, Wiebe N, Ezekowitz JA, Leung AA, Armstrong PW: Meta-analysis: betablocker dose, heart rate reduction, and death in patients with heart failure. Ann Intern Med 2009; 150:784-794.

11 Cullington D, Goode KM, Clark AL, Cleland JG: Heart rate achieved or beta-blocker dose in patients with chronic heart failure: which is the better target? Eur J Heart Fail 2012;14: 737-747.

12 Kalaria VG, Passannante MR, Shah T, Modi $\mathrm{K}$, Weisse $\mathrm{AB}$ : Effect of mitral regurgitation on left ventricular thrombus formation in dilated cardiomyopathy. Am Heart J 1998; 135(2 pt 1):215-220.

13 Lip GY, Gibbs CR: Does heart failure confer a hypercoagulable state? Virchow's triad revisited. J Am Coll Cardiol 1999;33:1424-1426.

14 Pullicino P, Thompson JL, Barton B, Levin B, Graham S, Freudenberger RS: Warfarin versus aspirin in patients with reduced cardiac ejection fraction (WARCEF): rationale, objectives, and design. J Card Fail 2006;12:39-46.

15 Homma S, Thompson JL, Pullicino PM, Levin B, Freudenberger RS, Teerlink JR, Ammon SE, Graham S, Sacco RL, Mann DL, Mohr JP, Massie BM, Labovitz AJ, Anker SD, Lok DJ, Ponikowski P, Estol CJ, Lip GY, Di Tullio MR, Sanford AR, Mejia V, Gabriel AP, del Valle ML, Buchsbaum R: Warfarin and aspirin in patients with heart failure and sinus rhythm. N Engl J Med 2012;366:1859-1869.

16 Benetos A, Rudnichi A, Thomas F, Safar M, Guize L: Influence of heart rate on mortality in a French population: role of age, gender, and blood pressure. Hypertension 1999;33: 44-52.

17 Hsia J, Larson JC, Ockene JK, Sarto GE, Allison MA, Hendrix SL, Robinson JG, LaCroix AZ, Manson JE: Resting heart rate as a low tech predictor of coronary events in women: prospective cohort study. BMJ 2009;338:b219.

18 Mao Q, Huang JF, Lu X, Wu X, Chen J, Cao J, $\mathrm{Li}$ J, Gu D: Heart rate influence on incidence of cardiovascular disease among adults in China. Int J Epidemiol 2010;39:1638-1646.

19 Julius S, Palatini P, Kjeldsen SE, Zanchetti A, Weber MA, McInnes GT, Brunner HR, Mancia G, Schork MA, Hua TA, Holzhauer B, Zappe D, Majahalme S, Jamerson K, Koylan $\mathrm{N}$ : Usefulness of heart rate to predict cardiac events in treated patients with high-risk systemic hypertension. Am J Cardiol 2012;109: 685-692.

20 Lonn EM, Rambihar S, Gao P, Custodis FF, Sliwa K, Teo KK, Yusuf S, Bohm M: Heart rate is associated with increased risk of major cardiovascular events, cardiovascular and all-cause death in patients with stable chronic cardiovascular disease: an analysis of ONTARGET/ TRANSCEND. Clin Res Cardiol 2014;103: 149-159.

21 O’Neal WT, Qureshi WT, Judd SE, Meschia JF, Howard VJ, Howard G, Soliman EZ: Heart rate and ischemic stroke: the reasons for geographic and racial differences in stroke (REGARDS) study. Int J Stroke 2015;10: 1229-1235.

22 Bohm M, Schumacher H, Linz D, Reil JC, Ukena C, Lonn E, Teo K, Sliwa K, Schmieder RE, Sleight P, Yusuf S: Low resting heart rates are associated with new-onset atrial fibrillation in patients with vascular disease: results of the ONTARGET/TRANSCEND studies. J Intern Med 2015;278:303-312.

23 O’Neal WT, Almahmoud MF, Soliman EZ: Resting heart rate and incident atrial fibrillation in the elderly. Pacing Clin Electrophysiol 2015;38:591-597.

24 Morseth B, Graff-Iversen S, Jacobsen BK, Jorgensen L, Nyrnes A, Thelle DS, Vestergaard P, Lochen ML: Physical activity, resting heart rate, and atrial fibrillation: the Tromsø study. Eur Heart J 2016;37:2307-2313.

25 Williams B, Lacy PS, Thom SM, Cruickshank $\mathrm{K}$, Stanton A, Collier D, Hughes AD, Thurston H, O'Rourke M: Differential impact of blood pressure-lowering drugs on central aortic pressure and clinical outcomes: principal results of the conduit artery function evaluation (CAFE) study. Circulation 2006;113: 1213-1225.

26 Domanski MJ, Davis BR, Pfeffer MA, Kastantin M, Mitchell GF: Isolated systolic hypertension: prognostic information provided by pulse pressure. Hypertension 1999;34:375380 .

27 Fyhrquist F, Dahlof B, Devereux RB, Kjeldsen SE, Julius S, Beevers G, de Faire U, Ibsen H, Kristianson K, Lederballe-Pedersen O, Lindholm LH, Nieminen MS, Omvik P, Oparil S, Hille DA, Lyle PA, Edelman JM, Snapinn SM, Wedel H: Pulse pressure and effects of losartan or atenolol in patients with hypertension and left ventricular hypertrophy. Hypertension 2005;45:580-585.

28 DiFrancesco D: Funny channels in the control of cardiac rhythm and mode of action of selective blockers. Pharmacol Res 2006;53:399_ 406.

29 Swedberg K, Komajda M, Bohm M, Borer JS, Ford I, Dubost-Brama A, Lerebours G, Tavazzi L: Ivabradine and outcomes in chronic heart failure (SHIFT): a randomised placebo-controlled study. Lancet 2010;376:875885 . 